\title{
Advantages, indications, and the manufacturing of melted PVC waterpipe splints
}

\author{
W. J. THEUVENET, ${ }^{*}$ S. P. RUCHAL, D. J. SOARES \& \\ P. ROCHE \\ Anandaban Leprosy Referral Hospital, The Leprosy Mission, \\ Kathmandu, Nepal
}

Accepted for publication 7 February 1994

\begin{abstract}
Summary There are several indications when to use splints in the treatment of leprosy. PVC waterpipe is a cheap and easily available material in developing countries. Its advantages, indications, and the manufacturing of splints are described.
\end{abstract}

\section{Introduction}

There are several indications when to use splints in the treatment of the complications of leprosy, e.g. neuritis, arthritis, ulcers and after surgery. In the past Plaster of Paris (POP) was used for this purpose and lately several synthetic materials have been introduced, such as low density polyethylene granules ${ }^{1}$ or materials like Orthoplast which can be moulded by heating.

Leprosy remains mainly a problem of developing countries, but for the local manufacturing of splints, financial restrictions and lack of availability of materials are often limiting factors.

In this article we present our experiences gained with melted PVC waterpipe from 1987 onwards and compare this with other materials. The authors have more than 15 years' experience in hand surgery and the manufacturing of orthotics. Basic principles which are safe to apply in less experienced hands are discussed.

DISADVANTAGES OF SOME MATERIALS FOR MAKING SPLINTS

In Nepal we previously used locally made Plaster of Paris (POP) which was cheap but of poor quality. Imported POP like Gypsona was stronger but much more expensive.

A great disadvantage of POP is that it becomes soft when applied during the humid rainy season or when moistened by wound discharge. Low density polyethylene granules are slightly cheaper but not easy to obtain in Nepal. All the other heat-malleable materials are very expensive and need to be imported.

* Correspondence to: Dr W. J. Theuvenet, Consultant Plastic, Reconstructive and Hand Surgery, Lukas Hospital, P.O. Box 9014, 7300 DS Apeldoorn, The Netherlands 
ADVANTAGES OF MELTED PVC WATERPIPE AS GROUND MATERIAL FOR SPLINTS

In the search for a good alternative to the above-mentioned materials we have experimented at our hospital with PVC waterpipe for the past 6 years.

Apart from the fact that it can be moulded, PVC waterpipe has proved to have a great number of other advantages: 1, inexpensive (Figure 1); 2, lightness (Figure 2); 3, durability (Figure 3); 4, availibility in developing countries; 5, ease and simplicity in processing; 6, easy to clean; and 7, strength.

An ankle-foot back slab used as a resting splint costing US \$0.93, and weighing $125 \mathrm{~g}$, can be made within $15 \mathrm{~min}$ and with daily use will last at least 3 years.

Nowadays we only use POP splints for those indications where prefabricated PVC splints cannot suffice, as the latter cannot meet specific individual requirements.

\section{Indications for splints}

It is beyond the intention of this paper to provide a detailed description of each type of splint but merely to suggest indications, applications and risk factors in different types of PVC splints. As with all splints the actual manufacturing will also depend upon your own inventiveness, the individual requirements for each patient and the availability of other local materials. When you are in doubt about technical aspects do consult a handbook on splints or feel free to write to the authors.

$\begin{array}{lllc}\text { Material } & \text { Gypsona POP } & \begin{array}{c}\text { Polyethylene } \\ \text { granules }\end{array} & \text { PVC waterpipe } \\ \text { Ankle-foot Back slab } & \text { NRs. 185.00 } & \text { NRs. 90.00 } & \text { NRs. 28.00 } \\ & \text { (US \$6.17) } & \text { (US \$3.00) } & \text { (US \$0.93) }\end{array}$

Figure 1. Cost price comparison for the ankle-foot back slab in Nepali Rupees in 1991.

$\begin{array}{lccc}\text { Material } & \text { Gypsona POP } & \begin{array}{c}\text { Polyethylene } \\ \text { granules }\end{array} & \text { PVC waterpipe } \\ \text { Ankle-foot Back slab } & 1150 & 680 & 125\end{array}$

Figure 2. Weight (grams) comparison for an ankle-foot back slab.

\begin{tabular}{|c|c|c|c|}
\hline Material & Gypsona POP & $\begin{array}{c}\text { Polyethylene } \\
\text { granules }\end{array}$ & PVC waterpipe \\
\hline Ankle-foot Back slab & about 1 month & (*) 'durable' & at least 3 years \\
\hline
\end{tabular}

Figure 3. Durability comparison for an ankle-foot back slab. 


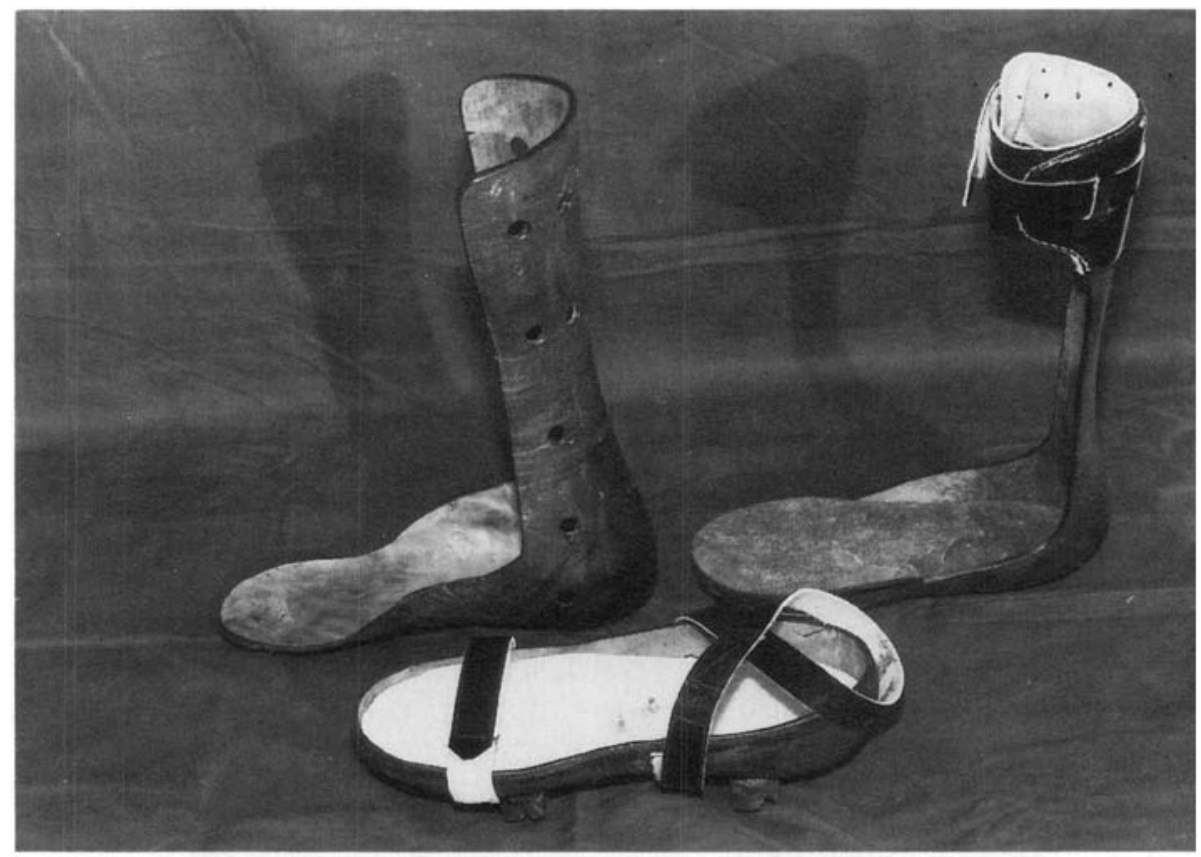

Figure 4. The ankle-foot back slab (L), rigid chappel (M) and footdrop inlay splint (R).

\section{RESTING SPLINTS (NONWEIGHT BEARING)}

\section{To assist in the healing of ulcers}

The most frequent complication of leprosy is the occurrence of ulcers due to loss of sensation and/or alteration of the muscle balance in an extremity.

It is of paramount importance first to diagnose WHY an ulcer has occurred and from this to draw a plan of HOW future recurrence could be PREVENTED.

Once this has been done a plan for treatment can be made. As a part of the treatment rest of the affected tissue is advised.

Examples are:

(a) the ankle-foot back slab (Figure 4) for ulcers of the foot and ankle. Holes can be drilled to promote ventilation;

(b) the cock-up splint (Figure 5) for ulcers of the wrist and dorsum of the hand; and

(c) the volar hand splint (Figure 5) for ulcers of the fingers and at the palmar side of the hand.

\section{To immobilize inflamed joints and rest nerves}

Arthralgia and neuritis in general occur in association with reactional episodes. ${ }^{2}$ Rest can support the medical treatment.

Examples are:

(a) the ankle-foot back slab for synovitis of the ankle joints or neuritis of the posterior tibial nerve. The ankle should be rested at about $30^{\circ}$ plantar flexion; 


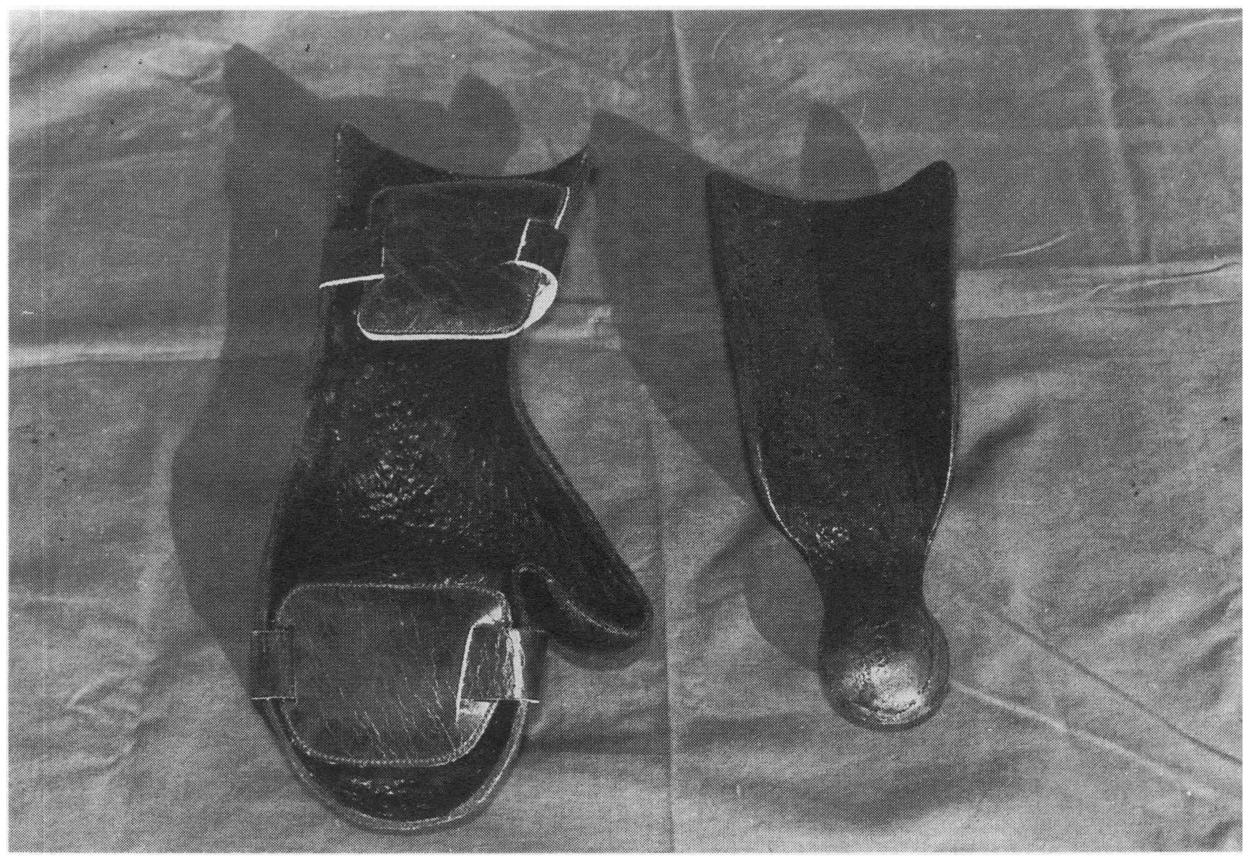

Figure 5. The volar hand splint (L) and cock-up splint (R).

(b) the long back slab for inflammation of the knee or neuritis of the popliteal nerve. The knee joint should be rested at about $30^{\circ}$ flexion;

(c) the elbow back slab to rest the ulnar nerve. The best position is about $45^{\circ}$ flexion; and (d) the cock-up splint to rest the wrist joint and median and ulnar nerves at this level. In order not to overstretch the nerves a maximum of $10-30^{\circ}$ dorsiflexion can be recommended.

\section{To immobilize (parts of) extremities after surgery}

In general this will be the case after septic surgery, arthrodesis, tendon transfers and tenotomy.

Examples are:

(a) the ankle-foot back slab to immobilize the joint either after septic surgery, tendon transfer, arthrodesis, or claw toe correction. After septic surgery a back slab is used which permits rest in $30^{\circ}$ plantar flexion; after an arthrodesis or claw toe correction the ankle should be supported in neutral position while after tendon transfer for footdrop correction one would need $75^{\circ}$ dorsiflexion; and

(b) the cock-up splint and volar hand splint after septic surgery on the wrist and hand.

In general muscle strengthening exercises of muscle groups of the affected limb will not be contraindicated and should even be encouraged as it promotes recuperation and can be an important psychological stimulus.

It should be remembered that stiffness will set in when normal joints are immobilized 


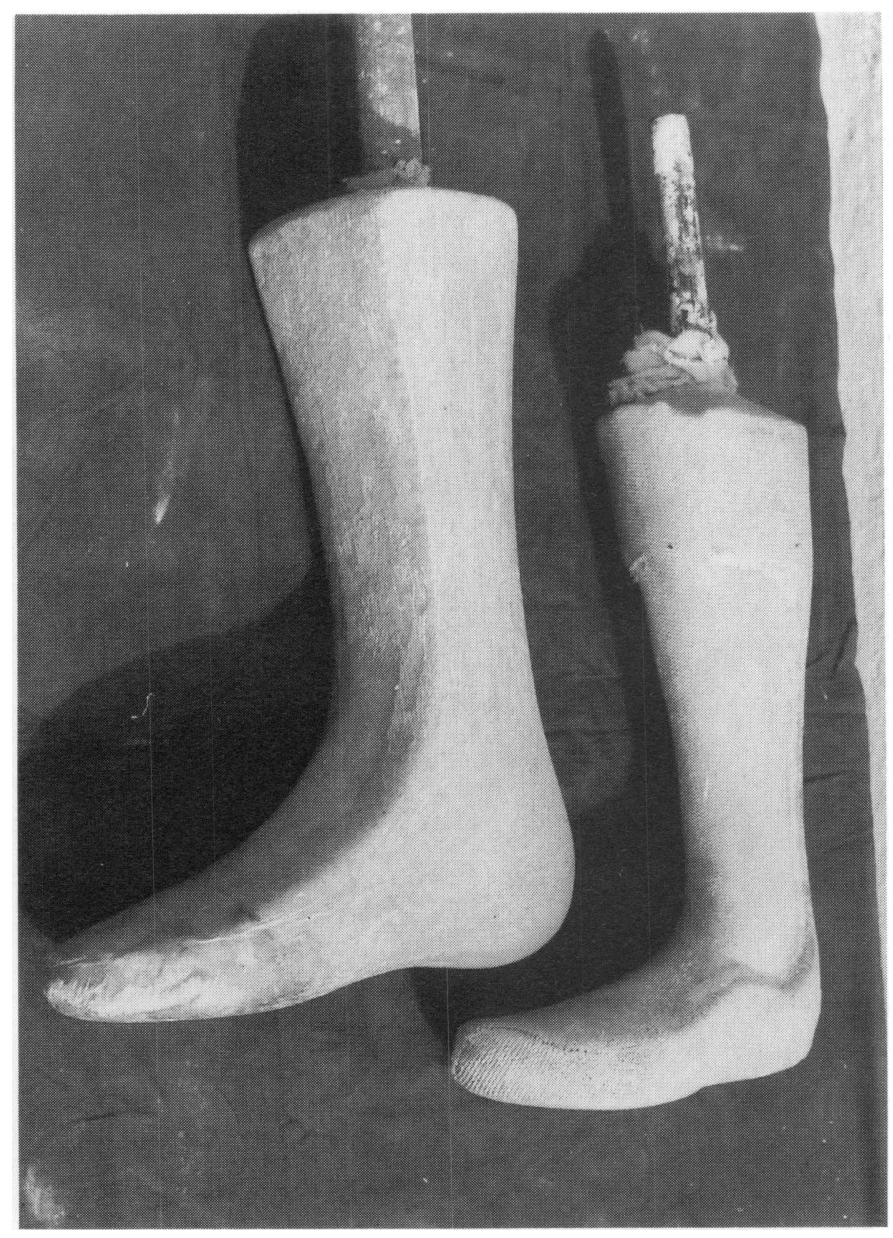

Figure 6. (a) Veneer impregnated POP forms for (L) ankle-foot back slab and (R) footdrop inlay splint. (b) The same for the volar hand splint and cock-up splint.

for longer than 3 weeks, and affected joints for longer than 2 weeks. When not contraindicated, controlled exercises of the immobilized joints are therefore advisable when splinting is indicated beyond these periods.

\section{POSITION MAINTENANCE SPLINTS}

More than for any other indication one should be aware of the increased risk of undue pressure when splints are used for the reduction of contractures in extremities with diminished sensation.

The splints are applied at the end of the exercises to overcome the contracture in order to maintain the achieved result. Avoidance of sharp edges and acute bends in any material used, adequate padding, a protocol for the application and regular inspections are mandatory. 


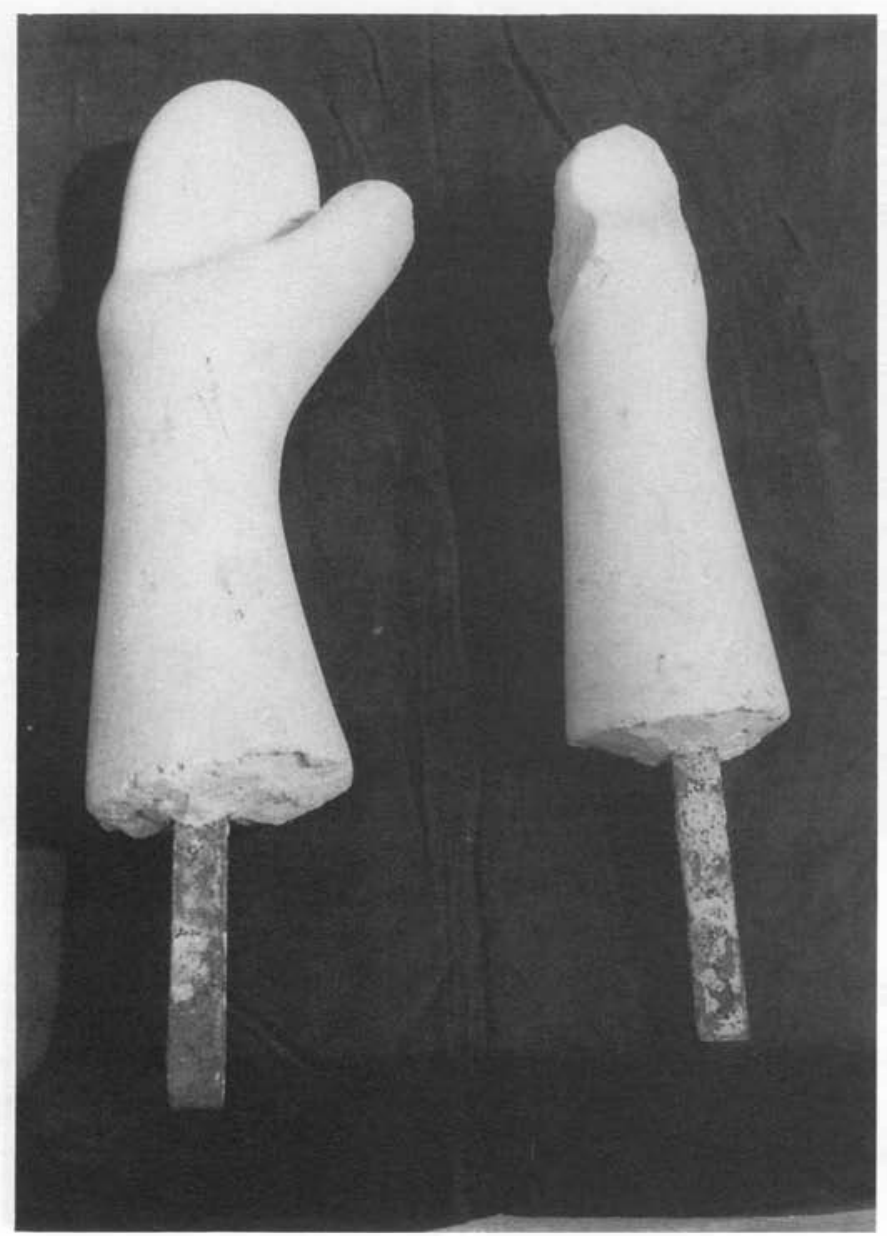

Figure 6 b.

To correct the contractures of soft tissues and joints

This is mostly done in preparation for reconstructive surgery. Two types can be differentiated; the passive splints in which correction is obtained by remoulding the splint in which the hand is immobilized (types (a) to (c)), and the dynamic splints (type (d)) with springs and elastic bands which provide the correcting forces and in which movement in the joints and tendons remains possible.

Examples are:

(a) the lumbrical splint holding the fingers with the metacarpophalangeal joints flexed and interphalangeal joints extended in order to correct flexion contractures of the fingers in the metacarpophalangeal and the proximal and distal interphalangeal joints and soft tissues. Potential pressure points are at the fingertips and the dorsum of the finger joints; (b) the volar hand dorsiflexion splint to stretch contracted flexor muscles (which of ten shorten in the claw hand), the wrist joint and the metacarpophalangeal joints; 


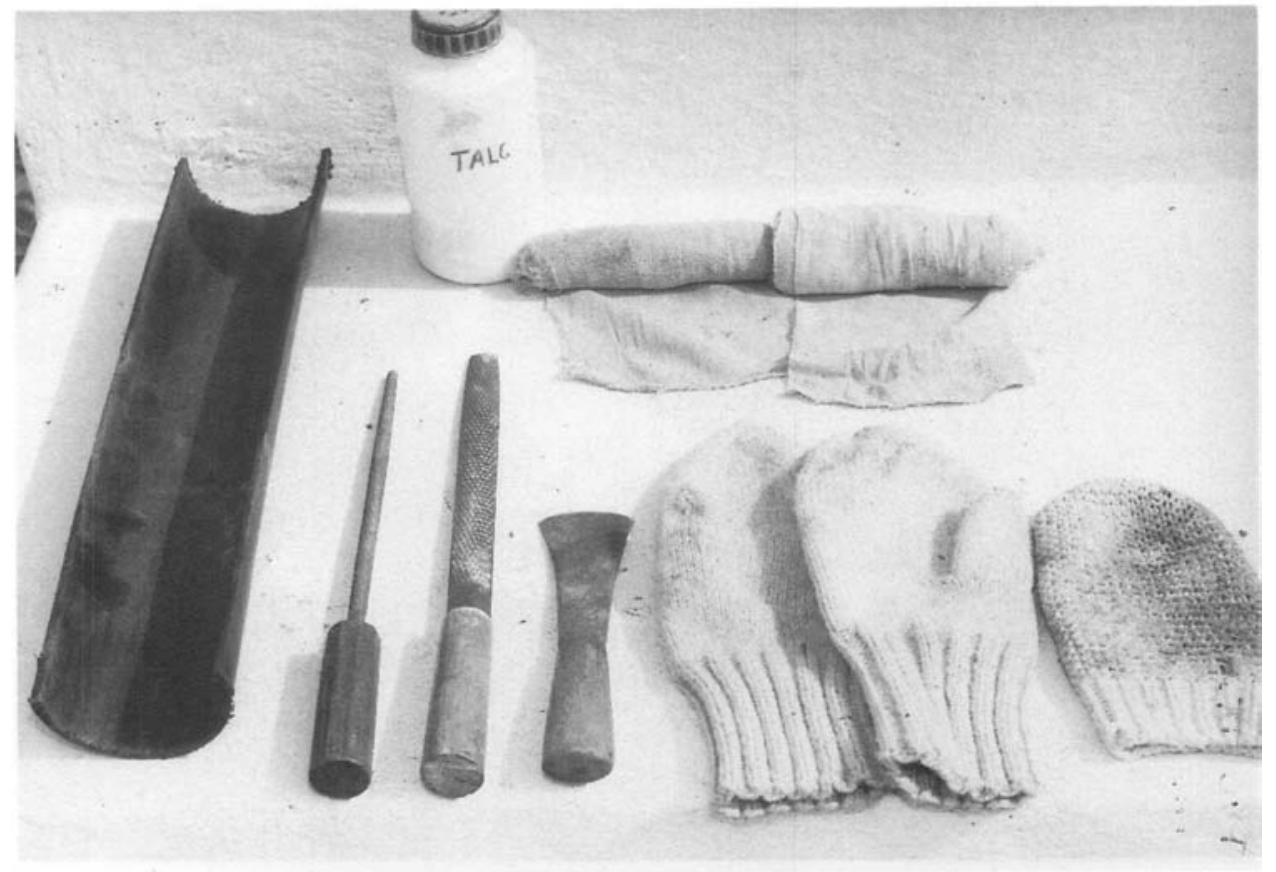

Figure 7. PVC waterpipe cut in half, files, knife, oven mittens (2 pairs), talc and elastic bandage.

(c) the thumb abduction splint to maintain the width of the first web-space after stretching exercises of the adductors and mobilization of the contracted trapezometacarpal joint, e.g. in preparation of an opponens plasty. A potential pressure point is the volar side of the basic phalanx; and

(d) the dynamic extension splint for dynamic extension traction of the interphalangeal joints. Potential pressure points are at the distal margin of the splint. The springs are attached with rivets about 2 inches distance from elbow level to the PVC.

\section{To limit movement in specific joints while other adjacent joints are normally used}

Examples are (see Figure 4):

(a) the foot drop inlay splint to support the ankle. This splint can be inserted in most canvas shoes and a MCR insole is placed upon the splint. Further padding can be introduced by the wearing of medium thickness cotton socks. Also in warmer climates this will be kinder to the skin as it absorbs moisture that would otherwise be trapped between the skin and the PVC. Please check the remaining space left for the foot. The calf part is fixed to the lower leg with a leather strap;

(b) the rigid chappel with MCR footbed to rest the forefoot. Rigidity is obtained by drilling holes in a piece of flattened PVC after which it is stitched between the margins of 


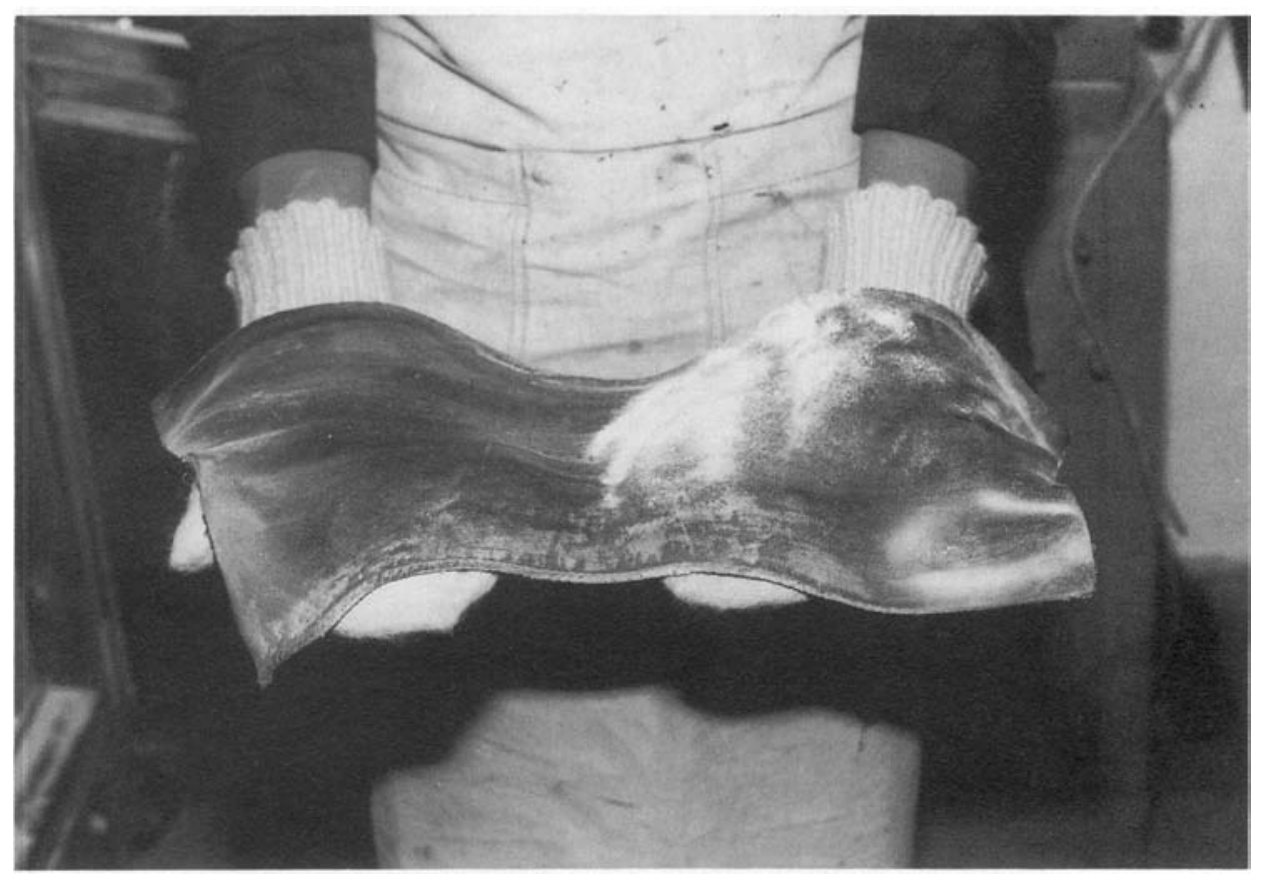

Figure 8. The melted PVC sprayed with talc.

the piece of tyre and the MCR as in normal MCR chappels. When used on even ground a rocker sole can be added. It is important to give a well-padded heel strap as much more strain is placed upon the skin of the ankle. In another article we hope to share our experiences with a semi-rigid moulded insole, which can be placed inside deep canvas shoes. This as an alternative for moulded boots.

\section{The manufacturing of splints from melted PVC waterpipe}

\section{MATERIALS}

Veneer impregnated POP or wooden forms of different sizes (Figures 6(a) and (b)). The first is used when a tailor-made splint is required and the latter for custom-made splints manufactured in series. One can veneer-impregnate POP by painting it with a veneer diluted with $5 \%$ kerosine.

PVC waterpipe of 4- to 7-inch diameter cut in half, files, knife, oven mittens (2 pairs), talc and elastic bandage (Figure 7).

Oven providing a temperature of $300^{\circ} \mathrm{C}$. We use a simple, locally made oven.

\section{PROCEDURE}

Place the PVC in the oven heated to $300^{\circ} \mathrm{C}$ for $15 \mathrm{~min}$. Make sure that there is good ventilation in the room. 


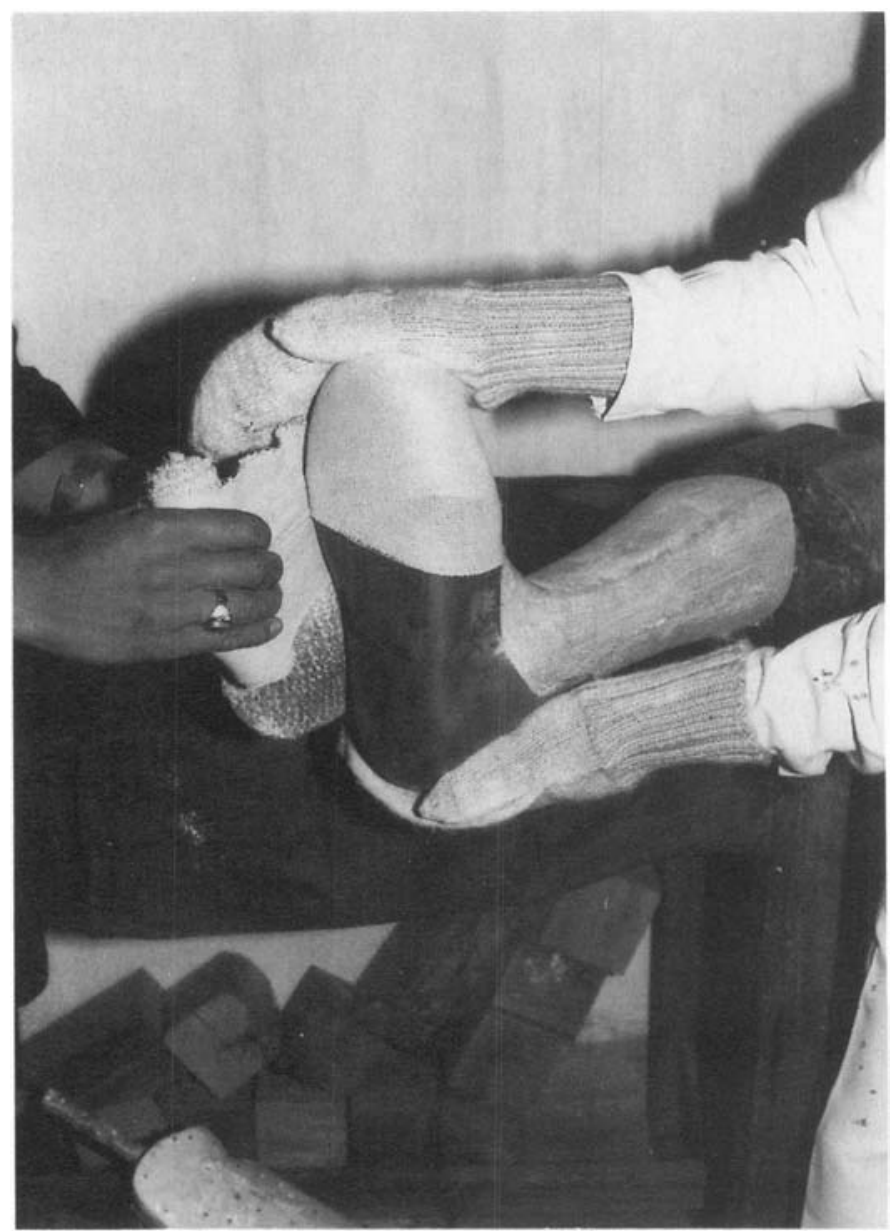

Figure 9. The PVC slab laid over the form and moulded to it with elastic bandage.

Take out the soft PVC slabs with the mittens and spray with talc (Figure 8).

The PVC will maintain its thickness but can be made thinner by stretching.

Place the PVC slab over the form and mould it by fixing it to the form with the elastic bandage for $5 \mathrm{~min}$ (Figure 9).

Cut and smooth the edges while the PVC is still warm (Figure 10).

In this phase the edges can still be slightly bent outward.

Drill holes in the splint for ventilation.

Line the splint with a layer of old blanket before applying it.

\section{Results and discussion}

In 1987 we made 126 PVC ankle-foot back slabs which have since been in continuous 


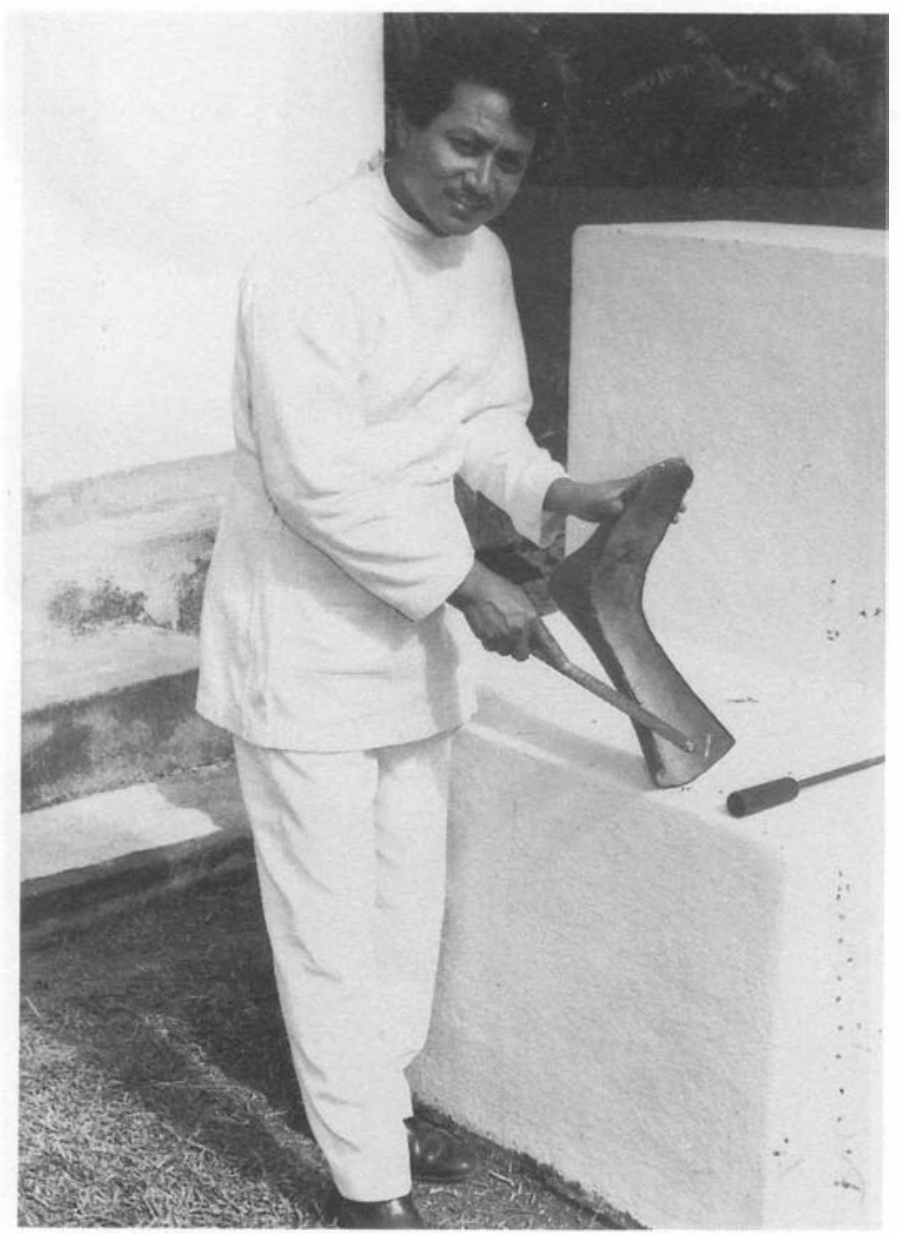

Figure 10. The cut edges are smoothed while the PVC is still warm.

use - 6 of these were taken home by patients. We sold 25 back slabs to other centres in Nepal, and 85 ankle-foot back slabs are still in use at the Anandaban Leprosy Hospital. About a third of these are now thin at the heel as patients who cannot use crutches sometimes use their back slab for pushing their wheeled stools.

We keep using these old splints for protecting forefoot ulcers. The PVC appears not to be affected by any of the ointments commonly in use.

The footdrop inlay splints only last about 3 months, which is the same as the lifespan of a footdrop spring. Because it is a dynamic splint, not a resting splint, it undergoes more stress, especially at the ankle where it of ten breaks.

The great advantage of the footdrop inlay splint is the much better cosmetic aspect of the affected foot as the inlay is not visible to other people. Another great advantage of PVC is that it does not create sharp edges when it breaks. Still, just as indicated for the foot and the footwear, regular inspections of the splints are mandatory. 
The footdrop inlay splints have been used in flat and hilly areas with the same result and lifespan.

Other types of resting and correcting splints of PVC are used in smaller numbers. Only those we have gained enough experience of are included in this paper.

We have not been able to use PVC for the resting splints for immobilization after tendon transfers in the hand, as balancing the transferred slips is a delicate issue calling for individual tailoring of the splint. It is of paramount importance to create a correct anatomical support for the transverse palmar arch in order to avoid undue stress to the intermetacarpal ligaments.

The introduction of PVC splints instead of Gypsona POP has resulted in a $40 \%$ reduction in the cost of making splints. The technique is now used in several centres throughout the country.

\section{Conclusion}

Splints made at Anandaban Hospital out of melted PVC waterpipe have proved in our experience to have major advantages in many indications over splints made from other materials.

\section{References}

1 Warren G, Tomlan J. Making polyethylene splints. The Star, 1990; 49: 4-6, 15.

2 Hastings RC. Leprosy, Churchill Livingstone, 1989. 